\title{
Tesla coil discharges guided by femtosecond laser filaments in air
}

\author{
Yohann Brelet ${ }^{1}$, Aurélien Houard ${ }^{1}$, Leonid Arantchouk ${ }^{2}$, Benjamin Forestier ${ }^{1}$, Yi Liu ${ }^{1}$, Bernard \\ Prade $^{1}$, Jérôme Carbonnel ${ }^{1}$, Yves-Bernard André ${ }^{1}$ and André Mysyrowicz ${ }^{1}$ \\ ${ }^{1}$ Laboratoire d'Optique Appliquée, ENSTA ParisTech, Ecole Polytechnique, CNRS, 91761, Palaiseau, France \\ ${ }^{2}$ Laboratoire de Physique des Plasmas, Ecole Polytechnique, CNRS, Palaiseau, France
}

A Tesla coil generator was designed to produce high voltage pulses oscillating at $100 \mathrm{kHz}$ synchronisable with a nanosecond temporal jitter. Using this compact high voltage generator we demonstrate reproducible meter long discharges in air at a repetition rate of $1 \mathrm{~Hz}$. Triggering and guiding of the discharges are performed in air by femtosecond laser filaments.

Intense ultrashort laser pulses propagating through atmosphere give rise to spectacular non-linear effects. Owing to a dynamic competition between non-linear optical Kerr self-focusing, and multiphoton ionization induced defocusing, a contracted beam of high peak intensity is formed over long distances. It leaves in its wake a long thin column of weakly ionized plasma (electron density $\sim 10^{16} \mathrm{~cm}^{-3}$ ). This process is usually referred to as filamentation ${ }^{1-3}$. Plasma filaments are useful for remote manipulation of high voltage discharges. They can trigger and guide megavolts discharges over several meters $^{4-5}$, carry high DC currents with reduced losses ${ }^{6}$ or deviate arcs from their natural path ${ }^{7}$. These properties are of great interest for applications such as the laser lightning $\operatorname{rod}^{7-9}$, virtual plasma antennas for radiofrequency transmission ${ }^{10}$ or high voltage switch.

In this paper, we report experiments of laser guided discharges obtained in air by high voltage bursts delivered by a compact Tesla coil. First we briefly present the Tesla coil developed for this experiment. Then we show results on the influence of laser filaments on the Tesla electric discharges in air.

The experimental setup is illustrated in Figure 1. The ENSTAmobile laser is used to create the plasma filaments in air. This Chirped Pulse Amplified laser chain can deliver femtosecond pulses at $800 \mathrm{~nm}$ with a peak power of 7 TW and an energy of $350 \mathrm{~mJ}$ per pulse at a maximum repetition rate of $10 \mathrm{~Hz}$. For the present experiment, the 50 fs pulses are stretched temporally to 700 fs by detuning the compressor stage of the system in order to avoid damages on steering mirrors and focusing lens. The laser beam is focused in air by a $5 \mathrm{~m}$ focal convex lens producing a tight bundle of about 50 filaments over a few meters around the geometrical focus of the beam. It produces a weakly ionized plasma column with an initial electron density of $\sim 10^{16} \mathrm{~cm}^{3}$, and a nanosecond recombination time ${ }^{11-12}$. We have verified that reducing the laser energy by an order of magnitude while keeping the same pulse duration gives same results as those presented below. Also, $50 \mathrm{fs}$ pulses with corresponding reduced peak intensity give the same plasma column.

The discharges are generated with a home-made Tesla coil. A Tesla coil is basically a voltage elevator transformer (see Figure 2). The coupling of two resonant R L C circuits allows obtaining voltage bursts at radiofrequencies with peak amplitude beyond $350 \mathrm{kV}$ at the output ${ }^{13-15}$. Capacitor $\mathrm{C}_{1}$ is first charged to a potential $\mathrm{V}_{\mathrm{C}}$ up to $12 \mathrm{kV}$. The primary circuit is then closed by a triggered trigatron $S_{1}$. The jitter of this switch is about 20 nanoseconds. The closing of the switch induces a free voltage oscillation in the primary circuit which is amplified and transferred to the secondary circuit by the mutual inductance $\mathrm{M}$ (see Fig. 2). Our Tesla coil is built with the following component values: $\mathrm{C}_{1} \approx 38 \mathrm{nF}, \mathrm{L}_{1} \approx 60 \mu \mathrm{H}, \mathrm{C}_{2}$ $\approx 48 \mathrm{pF}$ and $\mathrm{L}_{2} \approx 50 \mathrm{mH}$, so that both circuits are tuned to the same resonance frequency,

$$
f_{2}=f_{1}=\frac{1}{2 \pi \sqrt{L_{1} C_{1}}}=105 \mathrm{kHz}
$$

The evolution of the currents $\mathrm{i}_{1}(\mathrm{t})$ and $\mathrm{i}_{2}(\mathrm{t})$ in the circuit can be described by the following equations:

$$
\begin{aligned}
& \frac{1}{C_{1}} i_{1}(t)+R_{1} \frac{d i_{1}(t)}{d t}+L_{1} \frac{d^{2} i_{1}(t)}{d t^{2}}+M \frac{d^{2} i_{2}(t)}{d t^{2}}=0, \\
& \frac{1}{C_{2}} i_{2}(t)+R_{2} \frac{d i_{2}(t)}{d t}+L_{2} \frac{d^{2} i_{2}(t)}{d t^{2}}+M \frac{d^{2} i_{1}(t)}{d t^{2}}=0,
\end{aligned}
$$

where $\mathrm{M}=\mathrm{k}\left(\mathrm{L}_{1} \mathrm{~L}_{2}\right)^{1 / 2}$ is the mutual inductance and $\mathrm{k} \approx 0.2$ is the coupling coefficient. Solving these coupled equations with appropriate initial conditions ${ }^{13,15}$, we obtain a beating output voltage which is in very good agreement with our measurements (see Figure 3). The output voltage is measured by a resistive divider consisting of twenty $18-\mathrm{kOhm}$ resistances. Note that the maximum voltage in the secondary loop of the Tesla is reached during the first beat envelope after a delay of $\sim 25 \mu \mathrm{s}$.

Fig. 4 shows examples of guided discharge from the high voltage tip of the Tesla coil to a grounded electrode separated by $50 \mathrm{~cm}$. The pictures are time-integrated images of the visible radiation emitted by the guided HV discharges, recorded perpendicularly to the laser beam propagation axis with a standard CCD camera. The peak voltage on the high voltage electrode is close to $350 \mathrm{kV}$. This value is about $30 \%$ below the voltage threshold for spontaneous discharges. The 
same reduction in voltage required for electric discharges has been observed with high voltage supplied by a Marx generator $^{7}$. The plasma column produced by laser filamentation is adjusted to the immediate vicinity of both electrodes. The discharges are triggered and guided with $100 \%$ success. However successful operation requires a precise timing of the trigger with respect to the laser arrival time. Optimum repetability is achieved when the discharge is initiated by the laser $27 \mu$ s after triggering the switch $\mathrm{S}_{1}$ which corresponds to the peak of the voltage in the secondary loop. Setting the delay at 20 or $30 \mu \mathrm{s}$ (corresponding to a voltage minimum) deteriorates considerably the triggering probability. We note that there is a delay of 5 or $10 \mu$ s between the laser arrival time and the initiation of the discharge. A delay between laser pulse arrival and initiation of the discharge has been previously reported and discussed in terms of hydrodynamic expansion of the air heated by the initial plasma column ${ }^{16-17}$. We are planning a more detailed study of this retardation effect. We curently operate the system at $1 \mathrm{~Hz}$, but the Tesla could be easily operated at $100 \mathrm{~Hz}$ with appropriate cooling of the trigger system. We have measured the discharge current with a Rogowski coil placed around the cable connecting the second electrode to the ground. The peak current reaches several hundreds amperes. This current is increased by a factor two when compared to a natural discharge between the same electrodes. Interestingly we also obtain long guided discharges with a single electrode. Figure 5 shows an example of a two meters long discharge developping on each side of a spherical electrode charged at $350 \mathrm{kV}$.

In conclusion, we have developed a compact triggerable Tesla transformer able to produce high voltage AC pulses with a $20 \mathrm{~ns}$ temporal jitter. Using this Tesla coil together with a TW femtosecond laser we have demonstrated meter long guided electric discharges with high reliability. We have also shown for the first time that it is possible to obtain meter long guided discharges with a single electrode.

This project is supported by the French Direction Générale de l'Armement (grant n 200795 091). The authors would also like to thank F. Galet, J. Etivant and A. Dos Santos for their technical assistance.

\section{References}

1 A. Braun, G. Korn, X. Liu, D. Du, J. Squier, and G. Mourou, Opt. Lett. 20, 73 (1995).

2 S. L. Chin, S. A. Hosseini, W. Liu, Q. Luo, F. Théberge, N. Aközbek, A. Becker, V. P. Kandidov, O. G. Kosareva, H. Schroeder, Can. J. Phys. 83, 863 (2005).

3 A. Couairon and A. Mysyrowicz, Phys. Rep. 441, 47 (2007).

${ }^{4}$ H. Pépin, D. Comtois, F. Vidal, C. Y. Chien, A. Desparois, T. W. Johnston, J. C. Kieffer, B. La Fontaine, F. Martin, F. A. M. Rizk, C. Potvin, P. Couture, H. P. Mercure, A. Bondiou-Clergerie, P. Lalande, and I. Gallimberti, Phys. Plasmas 8, 2532 (2001).

${ }^{5}$ M. Rodriguez, R. Sauerbrey, H. Wille, L. Wöste, T. Fujii, Y.-B. André, A. Mysyrowicz, L. Klingbeil, K. Rethmeier, W. Kalkner, J. Kasparian, E. Salmon, J. Yu, and J.-P. Wolf, Opt. Lett. 27, 772 (2002).

${ }^{6}$ A. Houard, C. D’Amico, Y. Liu, Y. B. Andre, M. Franco, B. Prade, A. Mysyrowicz, E. Salmon, P. Pierlot, and L.-M. Cleon, App. Phys. Lett. 90, 171501 (2007).

${ }^{7}$ B. Forestier, A. Houard, I. Revel, M. Durand, Y. B. André, B. Prade, A. Jarnac, J. Carbonnel, M. Le Nevé, J. C. de Miscault, B. Esmiller, D. Chapuis, and A. Mysyrowicz, AIP Advances 2, 012151 (2012).

${ }^{8}$ X. M. Zhao, J.-C. Diels, A. Braun, X. Liu, D. Du, G. Korn, G. Mourou, and J. M. Elizondo, in Ultrafast Phenomena, Springer Series in Chemical Physics. New York: Springer-Verlag 60, 233 (1994).

9 J. Kasparian, M. Rodriguez, G. Méjean, J. Yu, E. Salmon, H. Wille, R. Bourayou, S. Frey, Y.-B. André, A. Mysyrowicz, R. Sauerbrey, J.-P. Wolf and L. Wöste, Science 301, 61 (2003).

${ }^{10}$ B. Forestier, A. Houard, M. Durand, Y. B. André, B. Prade, J.-Y. Dauvignac, F. Perret, Ch. Pichot, M. Pellet, and A. Mysyrowicz, Appl. Phys. Lett. 96, 141111 (2010).

${ }^{11}$ S. Tzortzakis, B. Prade, M. Franco, and A. Mysyrowicz, Opt. Commun. 181, 123 (2000).

${ }^{12}$ B. Zhou, S. Akturk, B. Prade, Y.-B. André, A. Houard, Y. Liu, M. Franco, C. D’Amico, E. Salmon, Z.-Q. Hao, N. Lascoux, and A. Mysyrowicz, Opt. Express 17, 11450 (2009).

${ }^{13}$ K. D. Skeldon, A. I. Grant and S. A. Scott, Am. J. Phys. 65, 744 (1997).

${ }^{14}$ K. L. Corum and J. F. Corum, Micro. Revija. 7, 36 (2001).

${ }^{15}$ D. G. Bruns, Am. J. Phys. 60, 797 (1992).

${ }^{16}$ F. Vidal, D. Comtois, C.-Y. Chien, A. Desparois, B. La Fontaine, T. W. Johnston, J.-C. Kieffer, H. P. Mercure, H. Pépin, and F. A. Rizk, IEEE Trans. on Plasma Science 28, 418 (2000).

${ }^{17}$ S. Tzortzakis, B. Prade, M. Franco, A. Mysyrowicz, S. Hüller, and P. Mora, Phys. Rev. E 64, 57401 (2001). 


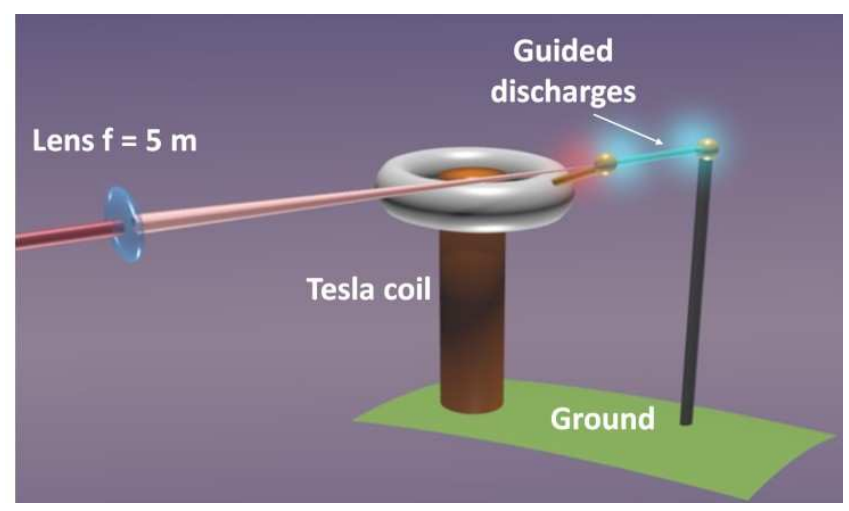

FIG. 1. Experimental setup. The Tesla coil delivers voltage up to $350 \mathrm{kV}$. The fs laser beam is focused and aligned to be in contact with the high voltage electrode connected to the Tesla terminal capacitor $\mathrm{C}_{2}$.
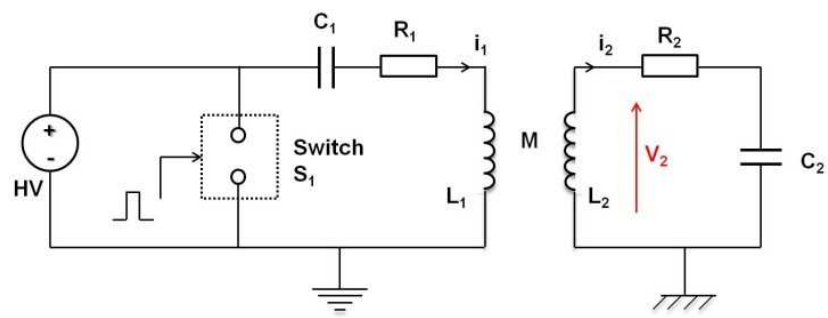

FIG. 2. Equivalent electrical scheme of our Tesla coil.

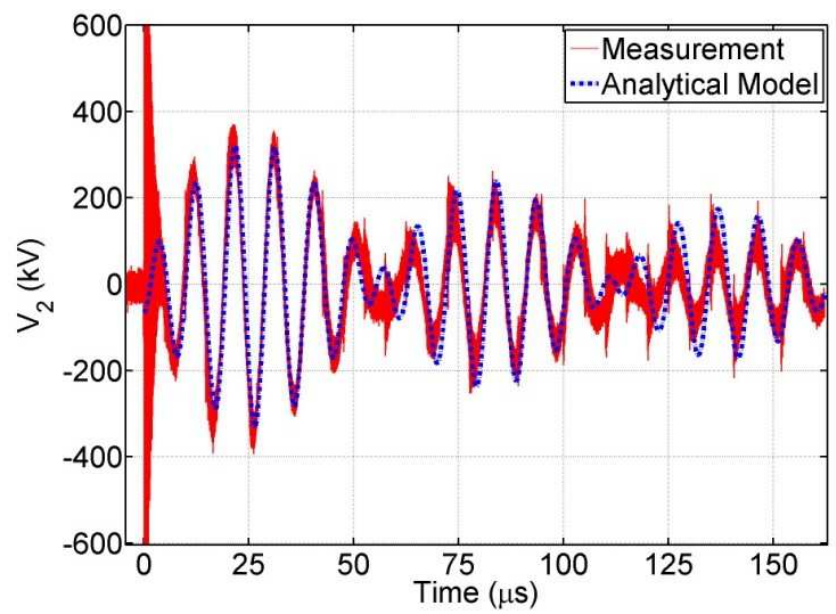

FIG. 3. Temporal waveform of voltage $\mathrm{V}_{2}(\mathrm{t})$ at the output of the Tesla coil measured (red continuous line) and calculated with the solution of Eq (1) (blue dotted line).

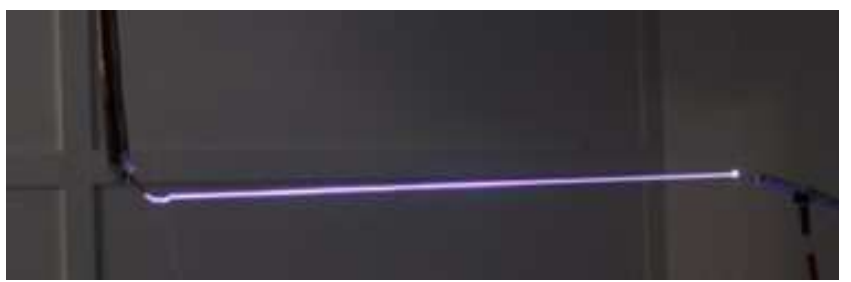

FIG. 4. Integrated image of guided Tesla discharges between two electrodes separated by $50 \mathrm{~cm}$. The laser comes from the left and the applied voltage peak is $350 \mathrm{kV}$. 


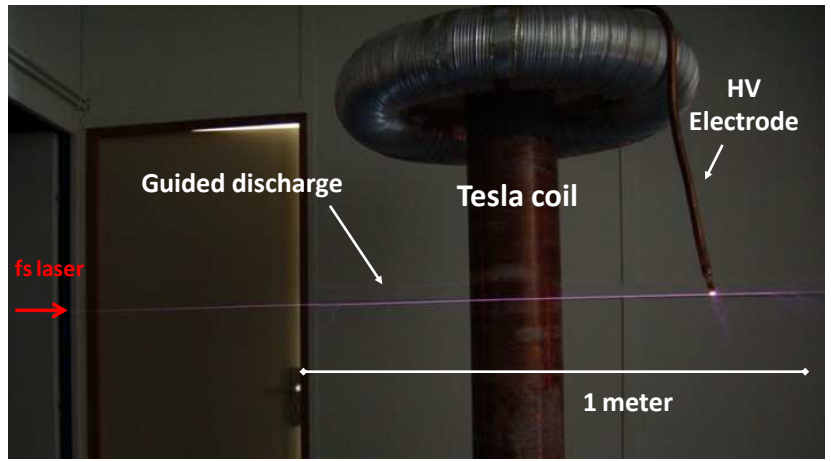

FIG. 5. Integrated image of the guided discharge with a single electrode applying a voltage peak of $350 \mathrm{kV}$. The laser comes from the left. 